Journal of Patient-Centered

\title{
Racial Disparity Among Women Diagnosed With Invasive Breast Cancer in a Large Integrated Health System
}

Maharaj Singh

Santhi D. Konduri

George C. Bobustuc

Amin B. Kassam

Richard A. Rovin

Follow this and additional works at: https://aah.org/jpcrr

Part of the Clinical Epidemiology Commons, Health Services Research Commons, Neoplasms Commons, Oncology Commons, Other Public Health Commons, and the Women's Health Commons

\section{Recommended Citation}

Singh M, Konduri SD, Bobustuc GC, Kassam AB, Rovin RA. Racial disparity among women diagnosed with invasive breast cancer in a large integrated health system. J Patient Cent Res Rev. 2018;5:218-28. doi: $10.17294 / 2330-0698.1621$

Published quarterly by Midwest-based health system Advocate Aurora Health and indexed in PubMed Central, the Journal of Patient-Centered Research and Reviews (JPCRR) is an open access, peer-reviewed medical journal focused on disseminating scholarly works devoted to improving patient-centered care practices, health outcomes, and the patient experience. 


\title{
Racial Disparity Among Women Diagnosed With Invasive Breast Cancer in a Large Integrated Health System
}

\author{
Maharaj Singh, PhD, ${ }^{1}$ Santhi D. Konduri, $\mathrm{PhD},{ }^{1}$ George C. Bobustuc, MD, ${ }^{2}$ Amin B. Kassam, MD, ${ }^{3}$ \\ Richard A. Rovin, MD ${ }^{3}$ \\ ${ }^{1}$ Aurora Research Institute, Aurora Health Care, Milwaukee, WI; ${ }^{2}$ Aurora Health Care, Milwaukee, WI; ${ }^{3}$ Aurora \\ Neuroscience Innovation Institute, Aurora Health Care, Milwaukee, WI
}
Purpose Reasons for the well-described disparity in outcomes between African American (AA) and non- Hispanic white (NHW) women with invasive breast cancer are unclear, making it difficult to identify solutions. This study examined the effects of demographics, biomarkers, tumor characteristics, cancer stage, morphology, and treatment variables on overall and cancer-free survival in these patient populations.

Methods We retrospectively reviewed data for 6231 patients diagnosed with invasive breast cancer throughout an integrated health system from January 2006 through March 2015. Included for analysis were $5023 \mathrm{NHW}$ and $413 \mathrm{AA}$ women. All category and continuous variables in the study were described in the two groups using appropriate statistics. Kaplan-Meier method of survival with log-rank test was used to compare the two racial groups (NHW and AA). Cox proportional hazards regression was used to find hazard ratios for the predictors of survival and recurrence-free survival probability. Propensity probability match method (1:1) was used to match 319 NSW women to 319 similar AA women. Matching was done using all significant predictors, including demographic variables.

Results Compared to NHW women, AA women presented with invasive breast cancer at a younger age $(P<0.001)$ and had a higher proportion of stage IV cancers $(P<0.001)$, which were more often infiltrating ductal carcinoma $(P<0.003)$ and poorly differentiated $(P<0.001)$. Within 10 -year follow-up, AA women had shorter overall and recurrence-free survival (log-rank $P<0.001$ ), were 1.4 times more likely to die $(P=0.009)$, and were twice as likely to have recurrence $(P<0.001)$ than NHW women. In the matched groups, overall survival was similar for AA and NHW (log-rank $\mathrm{P}=0.0793$ ); however, recurrence-free survival was higher in NHW than in AA women $(P=0.047)$.

Conclusions When presenting characteristics of AA and NHW women with invasive breast cancer are matched, disparity in overall mortality and rate of recurrence appears to be reduced or perhaps eliminated, suggesting invasive breast cancers in AA and NHW women respond similarly to treatment. Further study is needed to explore the true effect of biological factors; however, rectifying delivery of and access to care might be expected to mitigate, in large part, the racial disparity currently seen in breast cancer outcomes. (J Patient Cent Res Rev. 2018;5:218-228.)

Keywords invasive breast cancer; racial disparity; overall survival; recurrence; oncology; propensity match

A frican American (AA) women tend to be diagnosed with breast cancer at an earlier age and with less favorable tumor characteristics, leading to worse outcomes in terms of overall survival

Correspondence: Maharaj Singh, PhD, Aurora Research Institute, 960 N. 12th Street, \#4120, Milwaukee, WI 53233 (maharaj.singh@aurora.org) and recurrence-free survival (RFS) when compared with non-Hispanic white (NHW) women. ${ }^{1-3}$ According to the National Cancer Institute (NCI), cancer health disparities are defined as "adverse differences in cancer incidence (new cases), cancer prevalence (all existing cases), cancer death (mortality), cancer survivorship, and burden of cancer or related health conditions that exist among specific population groups in the United States." These specific population groups are often characterized by race and ethnicity. 
Complex and interrelated factors contribute to the observed disparities in cancer incidence and death among racial and ethnic groups, including socioeconomic status., ${ }^{4,5}$ According to NCI statistics from 2000 to 2004, the incidence of breast cancer among AA women was 118.3 per 100,000 whereas the incidence rate for NHW women was 132.5. Despite this, the death rate for AA women was 33.8 per 100,000 compared to 25.0 for NHW women. ${ }^{6}$

Although AA women have a lower incidence of breast cancer, their cancers are associated with a higher rate of mortality and recurrence compared to NHW women..$^{7-9}$ Many of the reasons for racial differences in mortality and cancer recurrence are not completely understood. Lower socioeconomic status was associated with an increase in mortality in a meta-analysis that included 20 studies, and the authors concluded that further exploration of associations between ethnicity and variation in primary tumor biology was needed. ${ }^{4}$ Additional proposed differences include cancer stage at presentation, differences in care, differences in treatment, and differences in (unfavorable) tumor biology. ${ }^{9-12}$ For example, triple-negative breast cancers are more common in AA women than in NHW women, and these cancers are associated with higher recurrence and decreased survival. ${ }^{13,14}$ Meta-analysis of 145 studies demonstrated a $22 \%$ increase in overall mortality risk in AA women, ${ }^{15}$ which increased to $27 \%$ in a follow-up meta-analysis of 20 studies from 1980 to $2005 .{ }^{4}$ When human epidermal growth factor receptor 2 (HER2)-positive cancers were combined with both estrogen receptor (ER)- and progesterone receptor (PR)-positive and -negative tumors, AA women demonstrated a $32 \%$ increased risk for mortality. Interestingly, when socioeconomic status was used as an adjusting factor, there were no racial differences in women presenting with stage I cancers of any subtype or in those presenting with stage II-IV ER/PR/HER2 subtypes, although the contribution of socioeconomic status to ethnic disparity varied widely within tumor subtype. ${ }^{5}$

In this study, we review the outcomes for AA and NHW women diagnosed with invasive breast cancer from January 2006 through March 2015 at a large integrated health care system based in Wisconsin. Demographics, biomarker expression, tumor characteristics, screening methods, treatment modalities, overall survival, and RFS for AA and NHW women were compared to determine the extent of racial disparity within the study cohort.

The amount and quality of data collected was rich enough to allow the creation of matched cohorts to test if any disparity remained when factors other than race were the same. We therefore created a matched cohort containing equal numbers of NHW and AA women, using the propensity-match technique, and compared survival and recurrence metrics, hypothesizing that when matched for demographic, molecular, histological, and treatment characteristics, overall survival and RFS would be similar between AA and NHW women. While demonstrating similarity in outcomes of matched patients would not determine clinical treatment decisions in individuals who present with breast cancer, it could steer researchers toward ascertaining the true causes of the differences in outcomes seen between AA and NHW women, possibly access to and engagement with health care services.

\section{METHODS \\ Study Population}

The cancer registry maintained by Aurora Health Care, an integrated health system and largest health care provider in Wisconsin, was accessed after institutional review board approval of this retrospective study. The medical records and cancer registry data for patients diagnosed with invasive breast cancer from January 2006 to March 2015 were reviewed. Only AA and NHW women diagnosed with invasive breast cancer were included in this study.

\section{Clinical Data}

For each woman diagnosed with invasive breast cancer, typical demographic data as well as cancer stage, grade, differentiation, tumor size, receptor (ER, PR, HER2) status, and treatments such as surgery, chemotherapy, hormonal therapy, immunotherapy, and radiation were recorded. Both breast cancer recurrence and all-cause mortality were included in the data.

\section{Statistical Analysis}

All categorical variables were described as count and percentage. Wherever appropriate, the chi-squared test and/or Fisher's exact test were used to compare the AA and NHW groups. Continuous variables were described 
as mean, median, and standard deviation. The KaplanMeier method was used to compare time-to-event data, including all-cause mortality and cancer recurrence over the 10-year follow-up. Study participants were considered to be at risk from the date of diagnosis of invasive breast cancer to the date of termination of follow-up (March 31, 2015), date of breast cancer recurrence (cancer-free survival analysis), or date of death, whichever occurred first.

Propensity score matching was performed based on demographic, prognostic, and treatment factors: race; age; screening mammography; biopsy; tumor morphology, differentiation, and size; expression of estrogen, progesterone, and HER2; chemotherapy; hormonal therapy; and immunotherapy. Variables for matching were identified by using univariate analysis for the demographics, biomarkers, tumor characteristics, and treatment variables. Using logistic regression, a predictive probability for whether a woman was likely to be AA or NHW was computed. Matching was done using an iterative process by matching probability for an AA woman to the same probability of a NHW woman. The predictive probabilities were matched up to 0.0001 precision using 1:1 (nearest-neighbor) matching. In this method, both groups (AA and NHW) are first sorted by the predicted probability. Then, the first AA woman is selected to find its closest match based on propensity score from NHW women. This procedure was repeated for all women. The mean difference logit score was 0.0185 , with standard error of 0.0169 .

According to post-hoc power calculation, an overall sample size of 638 subjects (of which 319 are in one group and 319 in the other group) achieved $92 \%$ power at a 0.05 significance level when the hazard ratio (HR) is actually 1.0. The equivalence ratio was 2.0. It was anticipated that the proportion of subjects in which the event (death, recurrence) was observed during the study would be 0.15 in each of the two groups. These calculations assumed that the HR remained constant throughout the study period and that Cox proportional hazards regression or the equivalence log-rank test was used to analyze the data.

All statistical tests were two-sided and used an alpha of 0.05. Analyses were conducted using $\mathrm{SAS}^{\circledR} 9.4$ software (SAS Institute Inc., Cary, NC).

\section{RESULTS}

Patient Demographic, Biomarker Expression, and Treatment

Data was retrospectively collected for 6231 women with a primary diagnosis of invasive breast cancer. For the purpose of this study, we excluded 795 women who were identified as Asian, American Indian, Asian Indian or Pakistani, Chinese, Filipino, Japanese, Korean, "other," or "unknown" race, or who were denoted as Hispanic (4.3\%). The remaining cohort of 5436 included 5023 NHW (92.4\%) and 413 AA (7.6\%) women (Table 1). During the follow-up period, 696 women (12.8\%) died and 779 women $(14.3 \%)$ had cancer recurrence.

Age: The median age of presentation was 52.4 years for AA women and 60 years for NHW women. The proportion of women 20 to 59 years old at diagnosis was significantly higher for AA than for NHW women $(\mathrm{P}<0.001)$.

Survival and Recurrence: Mean survival time was shorter for AA women compared to NHW women (3 years vs 3.7 years, $\mathrm{P}<0.001$ ). Both the rate of mortality $(17.0 \%$ vs $12.5 \%, \mathrm{P}=0.009)$ and cancer recurrence $(23.8 \%$ vs $13.6 \%, \mathrm{P}<0.001)$ were higher among AA women, while the probability of overall survival and RFS was lower (log-rank $\mathrm{P}<0.001)$. The difference in percentage in overall survival for the two groups at the end of $2,4,6,8$, and 10 years was $0.0,4.45,9.99,9.57$, and 4.42 , and the difference in RFS was $0.0,8.75,12.7$, 17.3 , and 17.1 , respectively.

Pathology, Grade, and Stage: The incidence of ductal carcinoma was higher among AA women, whereas lobular and other carcinomas were higher among NHW women $(\mathrm{P}<0.001)$. AA women also had more poorly differentiated tumors $(\mathrm{P}<0.001)$ and presented with more advanced (II, III, or IV) cancer stages $(\mathrm{P}<0.001)$. However, mean tumor size was similar across both groups ( $45.9 \mathrm{~cm}$ vs $53.2 \mathrm{~cm}, \mathrm{P}=0.351$ ).

Molecular Markers: The proportion of women who presented with ER-expressing $(\mathrm{P}<0.001)$ or $\mathrm{PR}$ expressing $(\mathrm{P}<0.001)$ tumors was lower among AA women, whereas the proportion of women with HER2expressing tumors $(\mathrm{P}=0.667)$ was similar among AA and NHW women. Among the remaining tumor subtypes, there were more NHW women with luminal 
Table 1. Comparison of Patient Demographic, Biomarker, Treatment Characteristics Between Black and White Women Diagnosed With Invasive Breast Cancer

\begin{tabular}{|c|c|c|c|c|}
\hline Characteristic & Overall $(\mathrm{N}=5436)$ & NHW $(n=5023)$ & AA $(n=413)$ & $P$ \\
\hline Age, $n(\%)$ & & & & $<0.0001$ \\
\hline 20-39 years & $271(5.0)$ & $230(4.6)$ & $41(9.9)$ & \\
\hline $40-59$ years & $2318(42.6)$ & $2106(41.9)$ & $212(51.3)$ & \\
\hline $60-79$ years & $2215(40.8)$ & $2076(41.3)$ & $139(33.7)$ & \\
\hline$\geq 80$ years & $632(11.6)$ & $611(12.2)$ & $21(5.1)$ & \\
\hline Mammography, n (\%) & & & & $<0.0001$ \\
\hline Yes & $2832(52.1)$ & $2661(53.0)$ & $171(41.4)$ & \\
\hline No & $2604(47.9)$ & $2362(47.0)$ & $242(58.6)$ & \\
\hline Biopsy, n (\%) & & & & 0.0133 \\
\hline Yes & 4952 (91.1) & $4562(90.8)$ & 390 (94.4) & \\
\hline No & $484(8.9)$ & $461(9.2)$ & $23(5.6)$ & \\
\hline Morphology (carcinoma), n (\%) & & & & 0.0026 \\
\hline Duct and lobular & $188(3.5)$ & $174(3.5)$ & $14(3.4)$ & \\
\hline Duct only & $4226(77.7)$ & $3877(77.2)$ & $349(84.5)$ & \\
\hline Lobular only & $555(10.2)$ & $532(10.6)$ & $23(5.6)$ & \\
\hline Other & $467(8.6)$ & $440(8.8)$ & $27(6.5)$ & \\
\hline Grade differentiation, ${ }^{*} \mathrm{n}(\%)$ & & & & $<0.0001$ \\
\hline Well & $1252(23.7)$ & $1185(24.3)$ & $67(16.5)$ & \\
\hline Moderate & $2365(44.8)$ & $2222(45.6)$ & $143(35.3)$ & \\
\hline Poor & $1663(31.5)$ & $1468(30.1)$ & $195(48.2)$ & \\
\hline Cancer stage, ${ }^{*}$ n (\%) & & & & $<0.0001$ \\
\hline I & $2538(48.2)$ & $2389(49.1)$ & 149 (37.6) & \\
\hline ॥ & $1798(34.2)$ & $1656(34.0)$ & $142(35.9)$ & \\
\hline III & $662(12.6)$ & $585(12.0)$ & 77 (19.4) & \\
\hline IV & $263(5.0)$ & $235(4.8)$ & $28(7.1)$ & \\
\hline Estrogen receptor, ${ }^{*} \mathrm{n}(\%)$ & & & & $<0.0001$ \\
\hline Positive & $4288(79.8)$ & $4037(81.3)$ & $251(61.4)$ & \\
\hline Negative & $1085(20.2)$ & $927(18.7)$ & $158(38.6)$ & \\
\hline Progesterone receptor, ${ }^{*} \mathrm{n}(\%)$ & & & & $<0.0001$ \\
\hline Positive & $3806(71.0)$ & $3,601(72.7)$ & $205(50.5)$ & \\
\hline Negative & $1554(29.0)$ & $1,353(27.3)$ & $201(49.5)$ & \\
\hline HER2, ${ }^{*}$ ( (\%) & & & & 0.6670 \\
\hline Positive & $680(13.5)$ & $631(13.6)$ & $49(12.8)$ & \\
\hline Negative & $4351(86.5)$ & $4017(86.4)$ & $334(87.2)$ & \\
\hline Cancer category, ${ }^{*} \mathrm{n}(\%)$ & & & & $<0.0001$ \\
\hline HER2 & $247(5.1)$ & $227(5.0)$ & $20(5.6)$ & \\
\hline Luminal A & $3169(65.2)$ & $2997(66.6)$ & $172(48.0)$ & \\
\hline Luminal B & $369(7.6)$ & $339(7.5)$ & $30(8.4)$ & \\
\hline Triple-positive & $324(6.7)$ & $313(6.7)$ & $11(3.1)$ & \\
\hline Triple-negative & $752(15.5)$ & $627(13.9)$ & $125(34.9)$ & \\
\hline Surgery, n (\%) & & & & 0.2427 \\
\hline Partial & $3406(62.6)$ & $3158(62.9)$ & $248(60.1)$ & \\
\hline Total & $689(12.7)$ & $626(12.5)$ & $63(15.2)$ & \\
\hline None & $1341(24.7)$ & $1239(24.7)$ & $102(24.7)$ & \\
\hline
\end{tabular}


Table 1 (continued). Comparison of Patient Demographic, Biomarker, Treatment Characteristics Between Black and White Women Diagnosed With Invasive Breast Cancer

\begin{tabular}{|c|c|c|c|c|}
\hline Characteristic & Overall $(\mathrm{N}=5436)$ & NHW $(n=5023)$ & AA $(n=413)$ & $P$ \\
\hline Radiation, ${ }^{*}$ ( $(\%)$ & & & & 0.1023 \\
\hline Yes & $3126(58.1)$ & $2911(58.4)$ & $215(54.2)$ & \\
\hline No & 2259 (41.9) & $2077(41.6)$ & $182(45.8)$ & \\
\hline Chemotherapy, ${ }^{*} \mathrm{n}(\%)$ & & & & $<0.0001$ \\
\hline Yes & $2641(48.6)$ & $2389(47.6)$ & $252(61.0)$ & \\
\hline No & $2793(51.4)$ & $2632(52.4)$ & $161(39.0)$ & \\
\hline Hormonal therapy, ${ }^{*} \mathrm{n}(\%)$ & & & & $<0.0001$ \\
\hline Yes & $3758(69.1)$ & $3554(70.8)$ & $204(49.4)$ & \\
\hline No & $1677(30.9)$ & $1468(29.2)$ & $209(50.6)$ & \\
\hline Immunotherapy, ${ }^{*} \mathrm{n}(\%)$ & & & & 0.5204 \\
\hline Yes & $116(2.0)$ & $109(2.2)$ & $7(1.7)$ & \\
\hline No & $5319(98.0)$ & $4913(97.8)$ & $406(98.3)$ & \\
\hline Mortality, n (\%) & & & & 0.0087 \\
\hline Dead & $696(12.8)$ & $626(12.5)$ & $70(16.9)$ & \\
\hline Alive & $4740(87.2)$ & $4397(87.5)$ & $343(83.1)$ & \\
\hline Cancer recurrence, ${ }^{*} \mathrm{n}(\%)$ & & & & $<0.0001$ \\
\hline Yes & $779(14.4)$ & $681(13.6)$ & $98(23.8)$ & \\
\hline No & $4645(85.6)$ & $4331(86.4)$ & $314(76.2)$ & \\
\hline Tumor size, ${ }^{*} \mathrm{n}($ mean $\pm \mathrm{SD})$ & $\begin{array}{c}5419 \\
(46.4 \pm 152.7)\end{array}$ & $\begin{array}{c}5008 \\
(45.9 \pm 152.2)\end{array}$ & $\begin{array}{c}411 \\
(53.2 \pm 158.9)\end{array}$ & 0.3510 \\
\hline Survival month, ${ }^{*} \mathrm{n}($ mean $\pm \mathrm{SD})$ & $\begin{array}{c}5436 \\
(43.4 \pm 29.6)\end{array}$ & $\begin{array}{c}5023 \\
(44.0 \pm 29.7)\end{array}$ & $\begin{array}{c}413 \\
(36.1 \pm 27.3)\end{array}$ & $<0.0001$ \\
\hline
\end{tabular}

AA, African American; HER2, hormone epidermal growth factor receptor 2; NHW, non-Hispanic white; SD, standard deviation.

*Indicates some values were missing for these characteristics.

A tumors and there were more AA women with triplenegative breast tumors $(\mathrm{P}<0.001)$.

Treatment: The proportion of women who received surgery of any type $(\mathrm{P}=0.243)$, radiation $(\mathrm{P}=0.102)$, and immunotherapy $(\mathrm{P}=0.520)$ was similar for both groups of women. More NHW women received hormonal therapy $(\mathrm{P}<0.001)$, and AA women were more likely to receive chemotherapy $(\mathrm{P}<0.001)$.

Screening: Fewer AA women received mammograms (41.4\% vs 53\%, $\mathrm{P}<0.001$ ), whereas fewer NHW women underwent a tumor biopsy ( $90.8 \%$ vs $94.4 \%, \mathrm{P}=0.013)$.

\section{Multivariate Analysis}

Multivariate analysis of overall survival and RFS showed that race (when adjusted for all other demographics, biomarker expression, tumor characteristics, and treatment modalities) was a significant predictor of mortality and cancer recurrence (Tables S1 and S2, online only). AA women had a 1.7 times higher risk of dying $(\mathrm{P}=0.0004)$ and a 1.4 times higher risk of cancer recurrence $(\mathrm{P}=0.0103)$ within 10 years.

Separate multivariate analyses were conducted for AA and NHW cohorts for all-cause mortality and cancer recurrence. Significant factors (adjusting for all other factors) for all-cause mortality in AA were presentation with later stages (III or IV vs I) of cancer (HR: 3.5, 95\% confidence interval $[\mathrm{CI}]$ : $1.4-9.2, \mathrm{P}=0.01$ for stage III; HR: 15.3, 95\% CI: 4.3-54.3, $\mathrm{P}<0.01$ for stage IV) and whether the woman underwent surgery (partial vs none) (HR: 0.4, 95\% CI: $0.2-0.9, \mathrm{P}=0.031$ ). In NHW women several factors were found to be 
significant: 1) whether the woman had been screened by mammography, 2) the grade of the tumor at presentation, 3) the stage of the cancer, 4) the size of the tumor, 5) HER2 expression, 6) whether she underwent surgery, 7) whether she was treated with chemotherapy, 8) whether she received hormonal therapy, and 9) whether she received radiation therapy.

For cancer recurrence our analyses resulted in similar findings. Significant factors for AA women were 1) whether the woman received a screening mammogram, 2) the stage of the cancer at presentation, 3) whether surgery had been performed, and 4) whether she had received radiation therapy. In NHW women significant predictors for tumor recurrence were 1) age, 2) mammographic screening, 3) grade of tumor at presentation, 4) stage of the cancer, 5) tumor size, 6) expression of either PR or HER2, 7) whether the women underwent surgery, and 8) treatment with chemotherapy, hormonal therapy, or radiation therapy.

\section{Propensity-Matched Cohort}

Propensity matching on the variables noted in Table 2 resulted in a 1:1 matched cohort of 319 AA and 319 NHW women. Table 2 also confirms the precision of the matching algorithm, as all the significant differences in the unmatched cohort became nonsignificant in the matched cohort. For the matched cohort (Table 3), overall survival was slightly better for NHW women but did not reach statistical significance $(\mathrm{P}=0.0793)$. RFS, however, was slightly longer for NHW women compared to AA women $(\mathrm{P}=0.0466)$. Figure 1 shows Kaplan-Meier curves for overall survival and RFS for unmatched and matched cohorts.

\section{DISCUSSION}

After reviewing outcomes of AA and NHW women with invasive breast cancer treated within a large health system, our findings were consistent with others published in the literature: 1) AA women had a higher mortality rate and rate of recurrence compared to their NHW counterparts; and 2) AA women presented with breast tumors carrying worse prognostic factors compared to NHW women. These prognostic factors included advanced stage at presentation with tumors that were more often poorly differentiated, less likely to express estrogen or progesterone positivity, and more likely to be triple-negative in makeup. As a result, the odds of dying and recurrence were 1.4 and 2.0 times higher, respectively, for AA women compared to NHW women. Among ER-, PR-, and HER2-positive cases, AA women had an increased risk of recurrence of approximately twofold. These findings are consistent with other similar population studies reported in the literature. ${ }^{16,17}$

Using multivariate logistic regression, we identified significant predictors of mortality and recurrence and found differences between AA and NHW women. For AA women, cancer stage and surgery were significant predictors for overall survival, whereas age, tumor characteristics, HER2 expression, and treatment were significant predictors of overall survival for NHW women. Among AA women, screening, cancer stage, surgery, and radiation were significant predictors for cancer recurrence, whereas in NHW women, age, tumor characteristics, HER2 and PR expression, and treatment were significant. Although our dataset did not have socioeconomic status indicators, Newman et al showed that lower socioeconomic status resulted in increased mortality. ${ }^{4}$ We would expect a similar effect within our patient cohort. Additionally, we assumed that the treatment plan for each patient was based on the limited set of biomarkers available.

In the propensity-matched cohorts, we controlled for patient characteristics, treatment regimens, and tumor characteristics. The only primary outcome measures that were significantly different on this analysis were mean length of survival and time to recurrence both shorter in AA women. Because we looked at allcause mortality and not cancer-specific mortality, the approximately 8-month difference in mean survival may be attributable to noncancer deaths related to poorer baseline health and more medical comorbidities in AA women. ${ }^{2}$ One of the limitations of propensity matching is that the sample size is reduced to the size of the smaller group. However, propensity matching does control variables and thus increases the sensitivity for the comparison.

It is important to understand the reason(s) underlying the race-related disparity in outcomes in women with breast cancer so that useful solutions can be identified. True biological differences are addressed differently than access to care. 
Table 2. Total and Propensity-Matched Cohorts, Divided by Race, for Women Diagnosed With Invasive Breast Cancer

\begin{tabular}{|c|c|c|c|c|c|c|}
\hline \multirow[b]{2}{*}{ Characteristic } & \multicolumn{3}{|c|}{ Unmatched cohorts } & \multicolumn{3}{|c|}{ Propensity-matched cohorts } \\
\hline & $\begin{array}{c}\text { NHW } \\
(\mathrm{N}=5023)\end{array}$ & $\begin{array}{c}\text { AA } \\
(N=413)\end{array}$ & $\boldsymbol{P}$ & $\begin{array}{c}\text { NHW } \\
(\mathrm{N}=319)\end{array}$ & $\begin{array}{c}\text { AA } \\
(N=319)\end{array}$ & $\boldsymbol{P}$ \\
\hline Age (years), n (\%) & & & $<0.0001$ & & & 0.1857 \\
\hline 20-39 years & $230(4.6)$ & $41(9.9)$ & & $26(8.2)$ & $25(7.8)$ & \\
\hline 40-59 years & $2106(41.9)$ & $212(51.3)$ & & $150(47.0)$ & $165(51.7)$ & \\
\hline $60-79$ years & $2076(41.3)$ & 139 (33.7) & & $112(35.1)$ & $112(35.1)$ & \\
\hline$\geq 80$ years & $611(12.2)$ & $21(5.1)$ & & $31(9.7)$ & $17(5.3)$ & \\
\hline Mammography, n (\%) & & & $<0.0001$ & & & 0.8737 \\
\hline Yes & $2661(53.0)$ & $171(41.4)$ & & $145(45.5)$ & $147(46.1)$ & \\
\hline No & $2362(47.0)$ & $242(58.6)$ & & $174(54.5)$ & $172(53.9)$ & \\
\hline Biopsy, n (\%) & & & 0.0133 & & & 0.8244 \\
\hline Yes & $4562(90.8)$ & $390(94.4)$ & & $308(96.5)$ & 309 (96.9) & \\
\hline No & $461(9.2)$ & $23(5.6)$ & & $11(3.5)$ & $10(3.1)$ & \\
\hline Morphology (carcinoma), n (\%) & & & 0.0026 & & & 0.7248 \\
\hline Duct and lobular & $174(3.5)$ & $14(3.4)$ & & $10(3.1)$ & $8(2.5)$ & \\
\hline Duct only & $3877(77.2)$ & $349(84.5)$ & & $269(84.3)$ & $279(87.5)$ & \\
\hline Lobular only & $532(10.6)$ & $23(5.6)$ & & $22(6.9)$ & $17(5.3)$ & \\
\hline Other & $440(8.8)$ & $27(6.5)$ & & $18(5.6)$ & $15(4.7)$ & \\
\hline Grade differentiation, ${ }^{*} \mathrm{n}(\%)$ & & & $<0.0001$ & & & 0.7699 \\
\hline Well & $1185(24.3)$ & $67(16.5)$ & & $55(17.2)$ & $57(17.9)$ & \\
\hline Moderate & $2222(45.6)$ & $143(35.3)$ & & 107 (33.5) & $114(35.7)$ & \\
\hline Poor & $1468(30.1)$ & $195(48.2)$ & & $157(49.2)$ & $148(46.4)$ & \\
\hline Cancer stage, ${ }^{*}$ n (\%) & & & $<0.0001$ & & & 0.7987 \\
\hline I & $2389(49.1)$ & $149(37.6)$ & & $125(39.2)$ & $137(43.0)$ & \\
\hline II & $1656(34.0)$ & $142(35.9)$ & & $127(39.8)$ & $121(37.9)$ & \\
\hline III & $585(12.0)$ & $77(19.4)$ & & $60(18.8)$ & $54(16.9)$ & \\
\hline IV & $235(4.8)$ & $28(7.1)$ & & $7(2.2)$ & $7(2.2)$ & \\
\hline Estrogen receptor, ${ }^{*} \mathrm{n}(\%)$ & & & $<0.0001$ & & & 0.6835 \\
\hline Positive & 4037 (81.3) & $251(61.4)$ & & $195(61.1)$ & $200(62.7)$ & \\
\hline Negative & 927 (18.7) & $158(38.6)$ & & $124(38.9)$ & 119 (37.3) & \\
\hline Progesterone receptor, ${ }^{*}$ ( (\%) & & & $<0.0001$ & & & 0.5245 \\
\hline Positive & 3601 (72.7) & $205(50.5)$ & & $171(53.6)$ & $179(56.1)$ & \\
\hline Negative & $1353(27.3)$ & $201(49.5)$ & & $148(46.4)$ & $140(43.9)$ & \\
\hline Chemotherapy, ${ }^{*}$ n (\%) & & & $<0.0001$ & & & 0.2308 \\
\hline Yes & $2389(47.6)$ & $252(61.0)$ & & $173(54.2)$ & $188(58.9)$ & \\
\hline No & $2632(52.4)$ & $161(39.0)$ & & $146(45.8)$ & $131(41.1)$ & \\
\hline Hormonal therapy, ${ }^{*} \mathrm{n}(\%)$ & & & $<0.0001$ & & & 0.4277 \\
\hline Yes & $3554(70.8)$ & $204(49.4)$ & & $164(51.4)$ & $174(54.6)$ & \\
\hline No & $1468(29.2)$ & $209(50.6)$ & & $155(48.6)$ & $145(45.4)$ & \\
\hline
\end{tabular}

AA, African American; NHW, non-Hispanic white.

*Indicates total numbers of patients are not equal to 5023 for NHW and 413 for AA for characteristic due to missing data. 
Table 3. Summary of Primary Outcome Measures for Unmatched and Matched Cohorts on Univariate Regression

\begin{tabular}{|c|c|c|c|c|c|c|}
\hline \multirow[b]{2}{*}{ Characteristic } & \multicolumn{3}{|c|}{ Unmatched cohort } & \multicolumn{3}{|c|}{ Matched cohort } \\
\hline & $\begin{array}{c}\text { NHW } \\
(\mathrm{N}=5023)\end{array}$ & $\begin{array}{c}\text { AA } \\
(N=413)\end{array}$ & $\boldsymbol{P}$ & $\begin{array}{c}\text { NHW } \\
(\mathrm{N}=319)\end{array}$ & $\begin{array}{c}\text { AA } \\
(\mathrm{N}=319)\end{array}$ & $\boldsymbol{P}$ \\
\hline Mortality, n (\%) & & & 0.0087 & & & 0.3226 \\
\hline Dead & $626(12.5)$ & 70 (19.9) & & $33(10.3)$ & $41(12.9)$ & \\
\hline Alive & $4397(87.5)$ & $343(83.1)$ & & $286(89.7)$ & $278(87.2)$ & \\
\hline Cancer recurrence, n (\%) & & & $<0.0001$ & & & 0.2291 \\
\hline Yes & $681(13.6)$ & $98(23.8)$ & & $44(13.8)$ & $55(17.2)$ & \\
\hline No & $4331(86.4)$ & $314(76.2)$ & & $275(86.2)$ & $264(82.8)$ & \\
\hline $\begin{array}{l}\text { Time to event (death, recurrence) } \\
\text { in years, median (IQR) }\end{array}$ & $3.41(4.0)$ & $2.5(3.50)$ & $<0.0001$ & $3.58(4.08)$ & $2.58(3.42)$ & 0.0041 \\
\hline Death, HR $(95 \% \mathrm{Cl})$ & ref & $\begin{array}{c}1.74 \\
(1.33-2.29)\end{array}$ & $<0.0001$ & ref & $\begin{array}{c}1.46 \\
(0.98-2.32)\end{array}$ & 0.1186 \\
\hline Recurrence, HR (95\% Cl) & ref & $\begin{array}{c}1.99 \\
(1.56-2.56)\end{array}$ & $<0.0001$ & ref & $\begin{array}{c}1.31 \\
(0.86-2.0)\end{array}$ & 0.2087 \\
\hline Death, OR $(95 \% \mathrm{Cl})$ & ref & $\begin{array}{c}1.43 \\
(1.10-1.88)\end{array}$ & 0.0089 & ref & $\begin{array}{c}1.30 \\
(0.79-2.08)\end{array}$ & 0.3235 \\
\hline Recurrence, OR $(95 \% \mathrm{Cl})$ & ref & $\begin{array}{c}1.98 \\
(1.56-2.53)\end{array}$ & $<0.0001$ & ref & $\begin{array}{c}1.30 \\
(0.85-2.0)\end{array}$ & 0.2299 \\
\hline Survival, log-rank K-M & & & $<0.0001$ & & & 0.0793 \\
\hline Recurrence, log-rank K-M & & & $<0.0001$ & & & 0.0466 \\
\hline
\end{tabular}

$A A$, African American; Cl, confidence interval; HR, hazard ratio; IQR, interquartile range; K-M, Kaplan-Meier; NHW, non-Hispanic white; OR, odds ratio; ref, reference.

Differences in tumor biology do exist, cannot be overlooked, and do present an opportunity for precision medicine intervention. For example, it has been reported that the tumor microenvironment in AA women demonstrates increased levels of resistin and interleukin-6, and that AA women have higher levels of proinflammatory tumor-associated macrophages and higher microvessel density. ${ }^{18}$ In our retrospective study, differences in tumor biology were not included in the database and thus were not analyzed between races. Our study did control for treatment, however, and showed that when AA and NHW women with similar characteristics received similar treatment, their outcomes also were similar. This suggests that the difference in outcomes in the unmatched cohort is due to differences in the receiving of treatment rather than in the effect of treatment.

Differences in health care equivalency have been documented. Annual age-adjusted breast cancer mortality rates in the United States, Chicago, and
New York City from 1980 to 2005 show that the mortality for each cohort was similar until 1991, when the curves started to diverge; NHW women demonstrated decreasing mortality while mortality among AA women increased. ${ }^{19}$ The authors concluded that the disparity in mortality related to disparity in access to care in three specific domains: the ability to access mammography, the quality of mammography available, and access to quality treatment. ${ }^{19}$ This data has informed sweeping changes in health care policy in Chicago; the Illinois Reducing Breast Cancer Disparities Act created the Breast Cancer Quality Consortium to improve the quality of mammography and helped expand the Illinois Breast and Cervical Cancer Program to provide screening, diagnosis, and treatment for all uninsured women in Illinois. ${ }^{20}$ These health care policy decisions were effective mortality for AA women in Chicago suffering from breast cancer decreased from $40.9 \%$ (1999-2005) to $35.2 \%(2006-2013){ }^{21}$ 

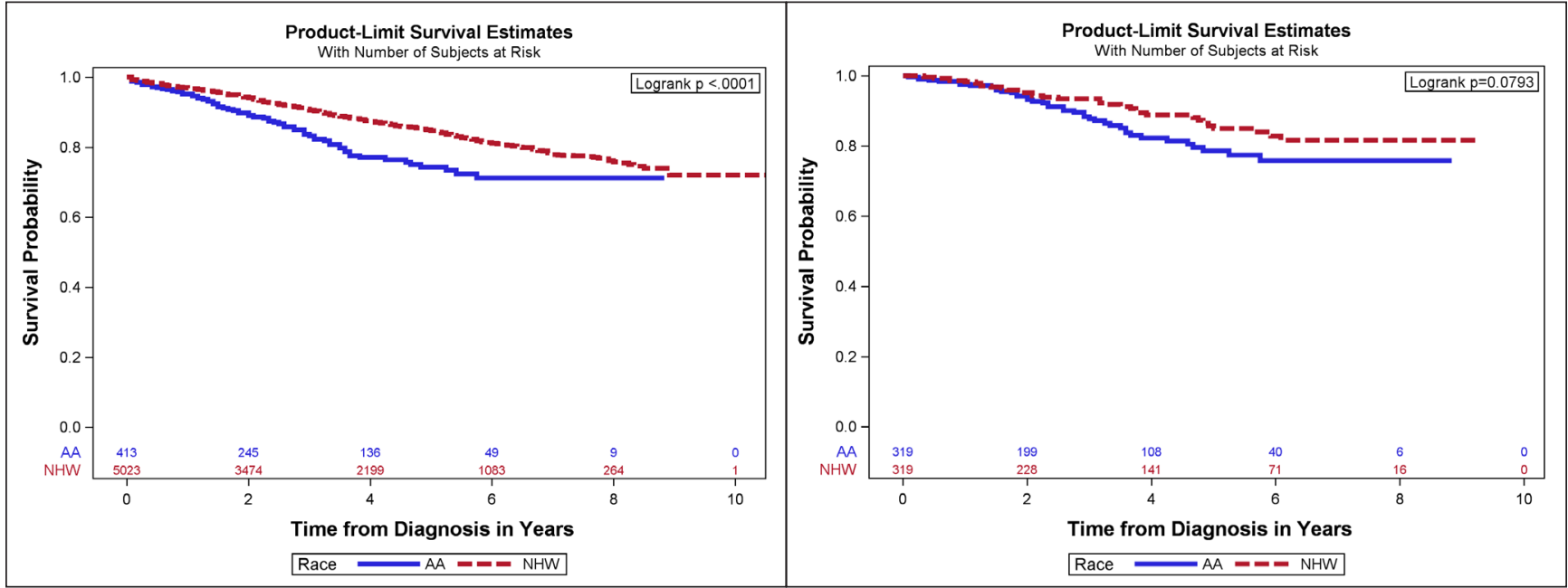

C

D
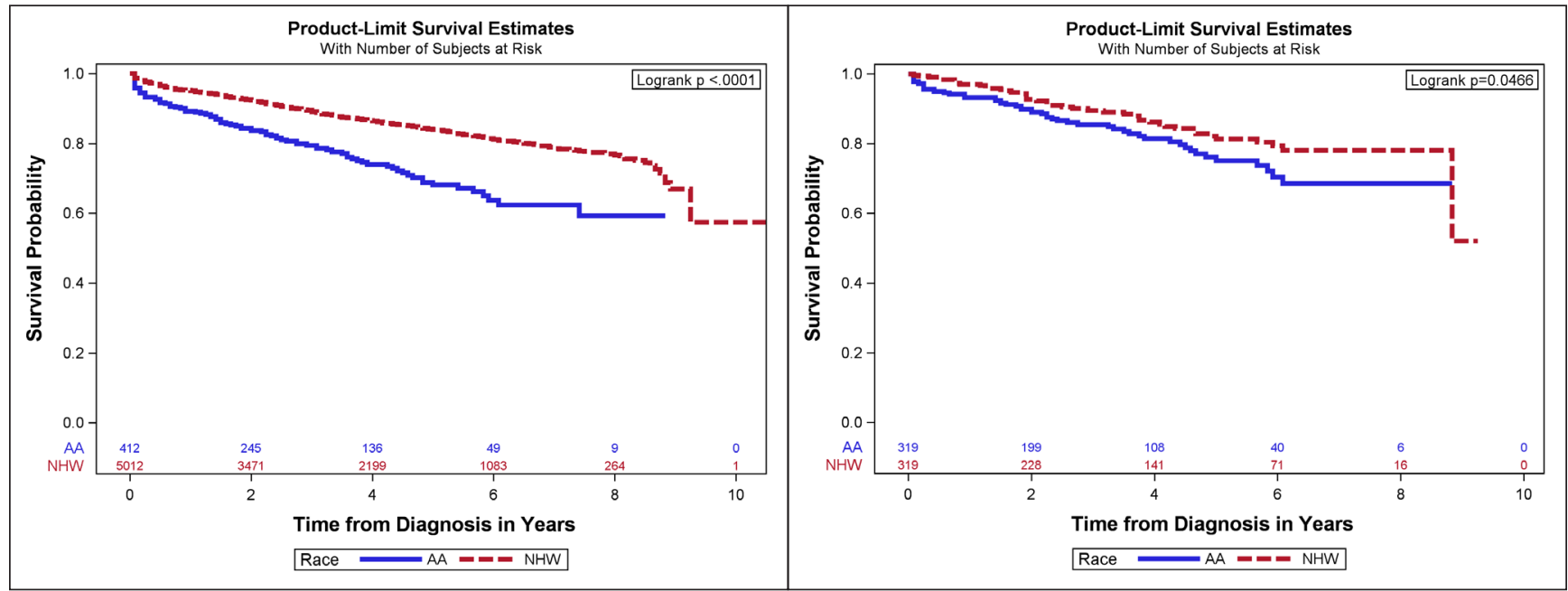

Figure 1. Overall and disease-free survival in African American (AA) women compared to non-Hispanic white (NHW) women. A: Overall 10-year survival for women diagnosed with invasive breast cancer for AA and NHW women. B: Overall 10-year survival for women diagnosed with invasive breast cancer for matched cohort of $A A$ and NHW women. C: Disease-free 10-year survival for women diagnosed with invasive breast cancer for AA and NHW women. D: Disease-free 10-year survival for women diagnosed with invasive breast cancer for matched cohort of $A A$ and NHW women.

\section{Limitations}

As noted throughout this report, there are limitations to our study methods and findings. The retrospective nature of data collection did not allow differences in tumor biology or socioeconomic variables between races to be analyzed. Though propensity score matching controls for variables to provide strong sensitivity in comparisons, a disadvantage of this statistical method is that sample size is reduced to the size of the smaller subpopulation. Not all patient biomarkers, which typically guide clinical treatment, were noted in the database. However, all available variables were analyzed as covariates. Among analyzed variables, a small number of values were missing from the dataset.

\section{CONCLUSIONS}

When presenting characteristics of AA and NHW women with invasive breast cancer are matched, disparity in overall mortality and rate of recurrence appears to be reduced or perhaps eliminated. NWH women did show an advantage in recurrence-free 
survival. Our novel use of propensity score matching confirms that when matched for biomarkers, tumor characteristics, and treatment, AA and NHW women with breast cancer had mostly similar outcomes. Therefore, differential outcomes are more likely due to differences in screening (which in turn affect distribution of age, stage, and grade of tumor at presentation), differences in baseline health, and differences in access to treatment (which can be societal, institutional, or cultural). Potential solutions to glaring racial disparities in breast cancer outcomes should look toward improving access to and delivery of care. Better RFS among NHW women might be due to factors - treatment adherence, socioeconomic status, or other unknown factors - beyond the scope of this study. Further study is needed to explore the effect of these factors.

\section{Patient-Friendly Recap}

- Due to oft-reported differences in outcome, race is viewed as a significant factor in treatment of invasive breast cancer.

- Authors compared two breast cancer cohorts (African American, non-Hispanic white) in which each patient was matched to a racial counterpart in terms of demographic, biomarker, tumor, cancer stage, and treatment characteristics.

- Overall survival was similar for African American and non-Hispanic white women after these other significant predictors and demographic variables were matched.

- If invasive breast cancers in both races respond similarly to treatment, rectifying delivery of and access to care might be a better goal to narrow the racial gaps seen in outcomes.

\section{Acknowledgments}

We would like to thank Lisa Robinson and the staff of Aurora Health Care's cancer registry for extracting the breast cancer data and Jennifer Jacob of JBJ Research \& Medical Writing (Rutland, VT) for helping in the technical writing.

\section{Author Contributions}

Study design: Singh, Konduri, Bobustuc, Rovin. Data acquisition or analysis: Singh, Konduri, Bobustuc, Rovin. Manuscript drafting: all authors. Critical revision: all authors.

\section{Conflicts of Interest}

None.

\section{References}

1. Iqbal J, Ginsburg O, Rochon PA, Sun P, Narod SA. Differences in breast cancer stage at diagnosis and cancerspecific survival by race and ethnicity in the United States. JAMA. 2015;313:165-73. CrossRef

2. Silber JH, Rosenbaum PR, Clark AS, et al. Characteristics associated with differences in survival among black and white women with breast cancer. JAMA. 2013;310:389-97. CrossRef

3. Tannenbaum SL, Koru-Sengul T, Miao F, Byrne MM. Disparities in survival after female breast cancer diagnosis: a population-based study. Cancer Causes Control. 2013;24:1705-15. $\underline{\text { CrossRef }}$

4. Newman LA, Griffith KA, Jatoi I, Simon MS, Crowe JP, Colditz GA. Meta-analysis of survival in African American and white American patients with breast cancer: ethnicity compared with socioeconomic status. J Clin Oncol. 2006;24:1342-9. CrossRef

5. Parise CA, Caggiano V. The influence of socioeconomic status on racial/ethnic disparities among the ER/PR/HER2 breast cancer subtypes. J Cancer Epidemiol. 2015;2015:813456. CrossRef

6. National Cancer Institute. Cancer health disparities. Reviewed March 11, 2008. https://www.cancer.gov/aboutnci/organization/crchd/cancer-health-disparities-fact-sheet. Accessed April 30, 2018.

7. $\mathrm{Wu} \mathrm{X}, \mathrm{Ye} \mathrm{Y}$, Barcenas $\mathrm{CH}$, et al. Personalized prognostic prediction models for breast cancer recurrence and survival incorporating multidimensional data. J Natl Cancer Inst. 2017;109(7). CrossRef

8. Hung MC, Ekwueme DU, Rim SH, White A. Racial/ethnicity disparities in invasive breast cancer among younger and older women: an analysis using multiple measures of population health. Cancer Epidemiol. 2016;45:112-8. CrossRef

9. DeSantis CE, Fedewa SA, Goding Sauer A, Kramer JL, Smith RA, Jemal A. Breast cancer statistics, 2015: convergence of incidence rates between black and white women. CA Cancer J Clin. 2016;66:31-42. CrossRef

10. Chlebowski RT, Chen Z, Anderson GL, et al. Ethnicity and breast cancer: factors influencing differences in incidence and outcome. J Natl Cancer Inst. 2005;97:439-48. CrossRef

11. Polite BN, Olopade OI. Breast cancer and race: a rising tide does not lift all boats equally. Perspect Biol Med. 2005;48(1 Suppl):S166-75. CrossRef

12. Sarker M, Jatoi I, Becher H. Racial differences in breast cancer survival in women under age 60. Breast Cancer Res Treat. 2007;106(1):135-41. CrossRef

13. Newman LA, Kaljee LM. Health disparities and triplenegative breast cancer in African American Women: a review. JAMA Surg. 2017;152:485-93. CrossRef

14. Amirikia KC, Mills P, Bush J, Newman LA. Higher population-based incidence rates of triple-negative breast cancer among young African-American women: implications for breast cancer screening recommendations. Cancer. 2011;117:2747-53. CrossRef

15. Newman LA, Mason J, Cote D, et al. African-American ethnicity, socioeconomic status, and breast cancer survival: a meta-analysis of 14 studies involving over 10,000 African-American and 40,000 white American patients with carcinoma of the breast. Cancer. 2002;94:2844-54. CrossRef 
16. Kabat GC, Ginsberg M, Sparano JA, Rohan TE. Risk of recurrence and mortality in a multi-ethnic breast cancer population. J Racial Ethn Health Disparities. 2017;4:1181-8. CrossRef

17. Jemal A, Robbins AS, Lin CC, et al. Factors that contributed to black-white disparities in survival among nonelderly women with breast cancer between 2004 and 2013. J Clin Oncol. 2018;36:14-24. CrossRef

18. Deshmukh SK, Srivastava SK, Tyagi N, et al. Emerging evidence for the role of differential tumor microenvironment in breast cancer racial disparity: a closer look at the surroundings. Carcinogenesis. 2017;38:757-65. CrossRef

19. Whitman S, Ansell D, Orsi J, Francois T. The racial disparity in breast cancer mortality. J Community Health. 2011;36:588-96. $\underline{\text { CrossRef }}$
20. Hunt BR, Hurlbert MS. Black:white disparities in breast cancer mortality in the 50 largest cities in the United States, 2005-2014. Cancer Epidemiol. 2016;45:169-73. CrossRef

21. Sighoko D, Murphy AM, Irizarry B, Rauscher G, Ferrans C, Ansell D. Changes in the racial disparity in breast cancer mortality in the ten US cities with the largest African American populations from 1999 to 2013: the reduction in breast cancer mortality disparity in Chicago. Cancer Causes Control. 2017;28:563-8. CrossRef

(C) 2018 Aurora Health Care, Inc. 